\title{
Optimization Formulation of Spirulina platensis Chewable Tablet
}

\author{
Siti Fatmawati Fatimah ${ }^{1, \text { a) }}$, Raihan Novarida ${ }^{1, b)}$, Laela Hayu Nurani ${ }^{2, c)}$, Citra Aryani \\ Edityaningrum ${ }^{1, d)}$
}

\author{
${ }^{1}$ Pharmaceutical Technology Department, Faculty of Pharmacy, Universitas Ahmad Dahlan, Yogyakarta, 55166, \\ Indonesia. \\ ${ }^{2}$ Biological and Phytochemistry Department, Faculty of Pharmacy, Universitas Ahmad Dahlan, Yogyakarta, 55166, \\ Indonesia.
}

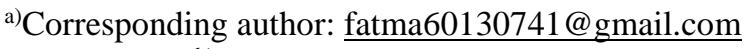

b)novarida69@gmail.com

c) $\underline{\text { laelafarmasi@yahoo.com }}$

d) citra.arianie@gmail.com

\begin{abstract}
Among various natural food sources, spirulina contains $\beta$-carotene which is higher than other sources that is used to overcome malnutrition. However, spirulina was widely marketed in the conventional form such as capsules and tablets which are less favorable for consumption. In order to increase its acceptability, it is formulated in the chewable tablet using direct press method that meets requirements and is acceptable to the community. This study aims to determine the valid of optimal formula for spirulina chewable tablets through the development of formulas on aerosil 200 (lubricant), and PEG 6000 (glidant). This was an experimental research which was carried out by optimizing the dry extract formula of Spirulina platensis using the Simplex Lattice Design (SLD) method with Aerosil 200 as a lubricant and PEG 6000 as a glidant. The tablet's physical properties observed were organoleptic, weight uniformity, tensile strength, friability, disintegration time. The result of physical properties test were analysed using one sample t-test with a $95 \%$ confidence level. Then, the optimum formula was conduct to hedonic test. The result of the spirulina chewable tablets optimum formula was consist of $25 \mathrm{mg}$ aerosil 200 (lubricant) and $5 \mathrm{mg}$ PEG 6000 (glidant) with $0.58 \%$ weight uniformity deviation, $4.52 \mathrm{kgf} / \mathrm{cm}^{2}$ tensile strength, $0.74 \%$ friability and all the tablets meets specification for disintegration time. The validation results showed that there were no significant differences in the physical properties of the SLD prediction results with the actual results. The hedonic test showed that optimum formula still need to add mask odour to minimize the characteristic aroma and the coating material to beautify physical appearance of spirulina the chewable tablet. The optimal formula for spirulina chewable tablets and fulfilling the quality requirements of traditional medicines is using $25 \mathrm{mg}$ aerosil 200 (lubricant) and 5 mg PEG 6000 (glidant).
\end{abstract}

Keywords: Spirulina, chewable tablet, aerosil 200, PEG 6000, simplex lattice design

\section{INTRODUCTION}

Many countries have used Spirulina to overcome malnutrition, especially in children. In Kongo, $10 \%$ of children who consumed spirulina have been saved from malnutrition [1]. Spirulina contains high amount of $\beta$ carotene which can provide weight gain and increase hemoglobin levels. According to Lorenz [2], the Food
Drug Association (FDA), 3 grams of spirulina powder contains $10 \mathrm{mg} \beta$-carotene, which is higher than other sources. In addition, Spirulina is proven to be a safe food for direct consumption [3] that contains essential amino acids; rare essential lipids such as gamma linolenic acid; mineral salts such as calcium, phosphorus, magnesium, zinc, copper, iron, chromium, manganese, sodium, potassium, and selenium; and 
vitamins such as beta carotene, vitamin A precursors, vitamins B1, B2, B6, B12, C, and E and enzymes [1]. Another fact, spirulina can provide weight gain and improve body function fat-free mass, increase hemoglobin levels and reduce anemia in HIV-infected or immune deficient adult patients within 12 weeks [4].

Spirulina is widely marketed in the form of conventional capsules and tablets which are less favorable for consumption. In order to increase spirulina's acceptability, it is necessary to make another dosage form that is chewable tablets. The direct compressing method is the best method to make the tablets and to decrease $\beta$-carotene oxidation and not stable to heat. The direct compressing method has shorter process stages than granulation, therefore it is expected that it can maintain its stability. However, the use of direct compressing method requires the formula of intermediate product flowability properties meet the quality target, therefore the weight uniformity and the tablet's dosage can be guaranteed.

This study used Aerosil 200 and PEG 6000 as a combination of lubricant ingredients. Aerosil 200 are able to increase the tablets friability. Aerosil 200 was chosen as a lubricant because it has a free-flowing, anticaking and anti-clogging properties. Aerosil 200 concentration as a lubricant (glidan) is $0.1-1.0 \%$ [5]. Meanwhile, polyethylene glycol (PEG) is an addition polymer of ethylene oxide and water. PEG 6000 as a lubricant helps to improve the flowability properties and the texture of the tablet's surface at $3 \%$ concentration [5]. The combination of the two lubricants is expected to maintain the flowability properties of the products to produce chewable tablet.

In the end, the spirulina chewable tablet must meet requirements and be acceptable to the community. The quality requirements of traditional medicine have several physical properties requirements of tablets that must be fulfilled, including organoleptic test parameters, weight similarities and disintegration time [6]. On the other hand, the physical characteristics parameter of chewable tablets according to the FDA [7] are organoleptic, weight similarities, hardness, fragility and disintegration time of the tablets. Based on these requirements, the formula can be developed based on the tablet's physical characteristics which consist of organoleptic tests, weight similarities, hardness and disintegration time of the tablet. According to tablet's physical characteristics data, the best formula was obtained by the Simplex Lattice Design (SLD) method and conducted to hedonic test to ensure the chewable tablet dosage form are well received by the community.

\section{METHOD}

Intruments and materials : The instrument used in this study were digital scales (Ohause), a set of extraction tools, evaporators (Heidolph), Buchner orifice, vacuum, mixing machines (Erweka AR 401), and tablet compressing machines (DELTA type VFD007S21A), hardness tester (PUSFIT), friability tester (CS-2), and disintegration tester (BJ-3). The materials used in this study were Spirulina platensis from Musthofa Herbal Klaten, ethanol 96\% (Chemic Laboratories), ludipress, aerosil 200, PEG 6000, and saccharine.

Simplicia Identification: Simplicia identification was carried out at the Biology Laboratory, FMIPA, Universitas Ahmad Dahlan.

Spirulina Extraction: The extraction method used the maceration method. The simplicia was taken as much as $1,405 \mathrm{~kg}$, then immersed in $5 \mathrm{~L}$ of $96 \%$ ethanol. It should be stirred approximately 2 hours then was soaked for 24 hours. The filtrate was filtered using Whattman filter paper with Buchner and vacuum funnel assistance. Filtrate remaceration of the first maceration with $96 \%$ ethanol (in the same ratio) $2 x$. The maserat mixture 1, 2 and 3 was evaporated and then the thick spirulina extract was pulverized by adding aerosil 200 gradualy until it becomes a dry extract.

Chewable tablet formulation: The orientation of lubricants with the lowest and highest concentrations of Aerosil 200 and PEG 6000 was done by inputting data on Design Expert 7.1.5. The result of 8 formulas of spirulina chewable tablet as predicted by SLD can be seen in table 1 . All ingredients were mixed using a cube mixer at $50 \mathrm{rpm}$ speed. The tablets were printed indoors with $25{ }^{\circ} \mathrm{C} \pm 2{ }^{0} \mathrm{C}$ temperature and $75 \% \mathrm{RH} \pm 5 \% \mathrm{RH}$ humidity.

Table I. Formula of spirulina chewable tablet

\begin{tabular}{lcccccccc}
\hline \multicolumn{1}{c}{ Component } & \multicolumn{8}{c}{ Quantity } \\
\cline { 2 - 9 } & F1 & F2 & F3 & F4 & F5 & F6 & F7 & F8 \\
\hline Spirulina dry extract (mg) & 250 & 250 & 250 & 250 & 250 & 250 & 250 & 250 \\
Ludipress (mg) & 245 & 245 & 245 & 245 & 245 & 245 & 245 & 245 \\
PEG 6000 (mg) & 20 & 25 & 5 & 15 & 25 & 5 & 10 & 15 \\
Aerosil 200 (mg) & 10 & 5 & 25 & 15 & 5 & 25 & 20 & 15 \\
Saccharin (mg) & 1 & 1 & 1 & 1 & 1 & 1 & 1 & 1 \\
Total (mg) & 526 & 526 & 526 & 526 & 526 & 526 & 526 & 526 \\
\hline
\end{tabular}

The test of material's flowability properties: Flow through an orifice done by one hundred grams of powder was put in the orifice. The flow through an orifice is qualified if it passes through the funnel in less than 10 seconds [8]. Angle of repose done by the granules were put into the orifice until it was full or as per the mark. Remove the granule holder in the orifice 
and keep them to make the tools not move. The angle of repose is calculated by means [8].

$$
\tan (\propto)=\frac{2 h}{d}
$$

Note: $\mathrm{h}=$ height of the granule formed, $\mathrm{d}=$ base's diameter of the granule formed

The test of tablet quality parameters: Based on BPOM [6], the physical properties test on spirulina chewable tablets including organoleptic observation, the uniformity of tablet weights, tablet breaking force and tensile Strength, tablet friability test, tablet disintegration time test. Organoleptic observations of tablets were included the shape, color, odor, taste, diameter and thickness of the tablets. Test the uniformity of tablet weights were took 20 chewable tablets of spirulina extract and weighed them one by one randomly. Then, calculate the average weight. If each spirulina chewable tablet is $526 \mathrm{mg}$, the requirement for weight similarity are not more than 2 tablets which each weight deviates $5 \%$ from the average weight and no tablet deviates $10 \%$ from the average weight [6]. Tablet breaking force and tensile strength were measured the dimensions of diameter of 6 tablets, then tested them using hardness tester. Recorded all the diameter and hardness of the tablet indicated on the device when the tablets were destroyed (F). Input the data in the Tensile Strength formula [8]

$$
\sigma \mathrm{x}=2 \mathrm{~F} / \pi \mathrm{D}
$$

Note: $\boldsymbol{\sigma x}$ : Tensile Strength, $\mathrm{F}=$ breaking force, $\boldsymbol{\pi}: 3$, 14 , D: tablet diameter

Tablet friability test were measured based on USP 38 [9] , a tablet that weigh equal to or less than $650 \mathrm{mg}$, the number of tablets tested is all tablets that weigh close to $6.5 \mathrm{~g}$, therefore the number of tablets tested are suitable with the formula (12 tablets). When the tablet is dust free, it is ready to be scaled (Wo). The tablet test used a friability tester with $25 \mathrm{rpm}$ speed for 4 minutes. Then, freed the tablets from dust and scaled (Wt). The formula to calculate the tablets' friability is as follows:

$$
\text { Friability }=\frac{(\mathrm{Wo}-\mathrm{Wt})}{\mathrm{Wo}_{\mathrm{o}}} \times 100 \%
$$

Tablet disintegration time test used a disintegration tester by putting 6 tablets into a basket-shaped tube, raising the tubes regularly 29-32 times per minute in a water medium with temperature of $35^{\circ}-39^{\circ} \mathrm{C}$. Make sure the tablet is destroyed before 15 minutes [8].

Optimum Formula Verification: The actual physical properties test results of optimum formula tablets based on Design Expert 7.1.5., were compared with the predicted values obtained from the program using SPSS statistical analysis of one sample t-test at a 95\% confidence level.

Hedonic Test: The hedonic test was carried out using a random sampling technique with a heterogeneous population of 20 respondents by filling out the questionnaire provided. The inclusion criterion was the condition of the healthy respondent's mouth, while the exclusion criterion was the condition of the unhealthy respondent's mouth condition, such as stomatitis. Each respondent gets the same opportunity to try the sample. The contents of the questionnaire included age, gender, date of birth, oral condition, appearance, odor, taste responses and suggestions. Appearance, smell and taste responses are grouped from the level of very dislike, dislike, like slightly, like, like very much.

\section{RESULT AND DISCUSSION}

Simplicia identification: Simplicia Spirulina platensis was derived from the freshwater cultivation with low minerals content compared to the seawater cultivation, therefore the simplicia does not smell too fishy. The results of macroscopic identification were following the results of parameters in the Certificate of Analysis (COA) Spirulina platensis from Musthofa Herbal Klaten. The microscopic identification of Spirulina platensis can be seen in table II. The results of identification were following the reference which is in filament and helix shape.

Table II. Simplicia macroscopic and microscopic identification of Spirulina platensis

\begin{tabular}{cccc}
\hline Identification & & Certification of Analysis & Sample \\
\hline Macroscopic & $\begin{array}{c}\text { Size } \\
\text { Color } \\
\text { Taste } \\
\text { Microscopic }\end{array}$ & $\begin{array}{c}\text { 99.8\% pass mesh 120 } \\
\text { Dark blue green } \\
\text { Mild, seaweed } \\
\text { odorless }\end{array}$ & $\begin{array}{c}\text { Pass 120 mesh } \\
\text { Dark blue green } \\
\text { Mild, seaweed } \\
\text { odorless }\end{array}$ \\
\cline { 3 - 4 } & & &
\end{tabular}


Extraction and drying of spirulina simplisia : The results of maserat were filtered and evaporated to decrease the ethanol levels. Maserat evaporated in the water bath at a temperature of $50{ }^{\circ} \mathrm{C}$ since $\beta$ - carotene compound is not stable against heat. $101,19 \mathrm{~g}$ obtained thick extracts were dried and pollinated with $94.23 \mathrm{~g}$ Aerosil 200. Thus, the yield obtained was $6.707 \%$ as seen in table III.

Table III. Rendement of spirulina dry extract powder with aerosil 200 as dryer

\begin{tabular}{ccc}
\hline Simplisia (gram) & Dry powder (gram) & Rendement (\%) \\
\hline 1,405 & 94.230 & 6.707 \\
\hline
\end{tabular}

Active material ingredient flowability properties: $\beta$ - carotene have easily oxidized properties, therefore it should be less exposed to the active materials during the tablets production process. The direct pressing method was considered as the most efficient method based on production period. Thus, it was necessary to ensure the flowability properties of spirulina dried extract active materials and intermediate product from the mixing results. The powders flowability in tablet compress process will affected to tablet weight and content uniformity of the dosage form [11].

Table IV. Spirulina dry extract powder flowability properties with aerosil 200 as dryer

\begin{tabular}{cc}
\hline Test of Powder flow & Result $(\mathbf{X} \pm$ SD) \\
\hline Flow through an orifice & $(9.2 \pm 0.36)$ second \\
Angle of repose & $(34.42 \pm 1.98)^{\circ}$ \\
\hline
\end{tabular}

Based on table IV, the test result of flow through an orifice on spirulina dried extracts was 9.2 seconds, while the angle of repose was $34.42^{\circ}$. On the other hand, the mixed intermediate product has flowability properties 8.17 second. The flowability properties of dried extract still met the requirement even though it was on the upper limit. But the flowability properties of intermediate product showed better results which can support the tablets making process with direct pressing method. The better flow properties make the granules are easier to compressed into tablets [12].

The presence of aerosil or colloidal silicon dioxide is small particle size and large specific surface area that gives it desirable flowability that are exploited to improve the flowability of dry powders in a number of processes such as tabletting. On the other hand, grades of PEG 6000 and above are available as free-flowing powders. Polyethylene glycol grades with molecular weights of 6000 and above can be used as lubricants, particularly for soluble tablets. The lubricant action is not as good as that of magnesium stearate but the stickiness may develop to increase the compactness of tablets.

Chewable tablet formulation: Aerosil 200 and PEG 6000 were combined as lubricant material. According to the Generic Drug Formularium, spirulina chewable tablet with $5 \mathrm{mg}$ aerosil 200 and $25 \mathrm{mg}$ PEG 6000 can produce spirulina chewable tablets with good physical properties without additional sweetener. The dryer used in spirulina extract was not mentioned, therefore the amount of Aerosil 200 and PEG 6000 used in this study which was in the range 5-25 mg needed to be optimized.

Spirulina chewable tablet critical quality attributes: Organoleptic tests performed included color, odor, taste, thickness and diameter of chewable tablets. Chewable tablets which in formulas 1 to 8 have a moss green color, a characteristic odor of spirulina, a sweet taste, with 0,5 cm thickness and 1,25 $\mathrm{cm}$ diameter, so that differences in the amount of aerosil 200 and PEG 6000 did not give significant differences organoleptically.

The tablets weight uniformity showed the weight variation of the produced tablet. Uniformed tablet weight would give a uniform dose. Based on FIGURE 1, all 8 formulas met the weight uniformity requirements. Formula 2 (aerosil 200, 5 mg, PEG $6000,25 \mathrm{mg}$ ) had $1,030 \%$ percent as the highest deviation, and Formula 1 (aerosil 200, $10 \mathrm{mg}$, PEG $6000,20 \mathrm{mg}$ ) has $0,501 \%$ percent as lowest deviation. The factors affecting the tablets weight uniformity were the uniformity of filling the die and the amount of material that should be loaded into the die. The uniformity of filling to the die was influenced by gravitational and density of the tablet components. PEG 6000 has a greater density compared to aerosil 200 and is sticky because it is hygroscopic. A lot more amount of Aerosil 200 may help to reduce the hygroscopic properties of PEG 6000, therefore it can reduce the stickiness and can flow easily to the die. The appropriate combination of aerosil 200 and PEG 6000 as a lubricant material can maintain the flowability properties of the mixture so that the quantity of intermediate product to the die is similar. The SLD equation for the response to uniformity of tablet weights was equation (3).

$$
\mathrm{Y}=0.62(\mathrm{~A})+0.95(\mathrm{~B})-0.65(\mathrm{~A})(\mathrm{B})
$$

Where, $\mathrm{Y}$ is weight uniformity response, $\mathrm{A}$ is Aerosil 200, and B is PEG 6000.

Equation (3) showed Aerosil 200 had a smaller positive coefficient value $(0,62)$ compared with PEG $6000(0.95)$, so aerosil 200 gave smaller effect toward 
the deviation of tablets average weight. The interaction between Aerosil 200 and PEG 6000 was negative (-0.65) which had an effect on decreasing the percentage of the deviation of tablets average weight so that the tablets weight uniformity was getting better.

Aerosil 200 as a glidant helped regulate the flow of particles by reducing adhesion between particles so that friction between particles would be reduced and able to reduce the deviation's percentage of the tablets average weight by increasing the compressibility of the tablet.

The relationship between Aerosil 200 and PEG 6000 to the response of tablets weight uniformity was shown through the graphic in FIGURE 1 which showed that the higher concentration of PEG 6000, the deviation of tablets average weight was increasing. The higher the concentration of Aerosil 200, the deviation of tablets average weight was getting decreased.

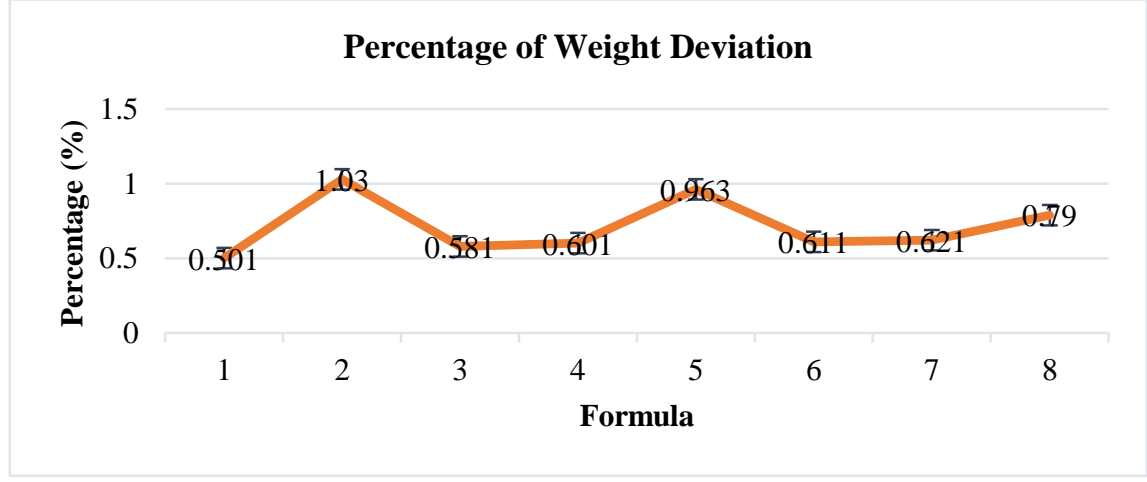

FIGURE 1. Percentage of Weight Deviation

Variations in the concentration of aerosil 200 and PEG 6000 affected the tablets tensile strength (FIGURE 2). The formula that had the highest tensile strength was formula 1 (aerosil 200, $10 \mathrm{mg}$, PEG 6000, $20 \mathrm{mg}$ ), it was $11.065 \mathrm{kp} / \mathrm{cm}^{2}$. The formula with the lowest tensile strength is Formula 7 (aerosil 200, $20 \mathrm{mg}$, PEG 6000, $10 \mathrm{mg}$ ) with an average value of $3.530 \mathrm{kp} / \mathrm{cm}^{2}$. The SLD equation for the components of Aerosil 200 and PEG 6000 toward the tablet tensile strength response was equation (2).

$$
\mathrm{Y}=4.89(\mathrm{~A})+7.66(\mathrm{~B})-2.38(\mathrm{~A})(\mathrm{B})
$$

Where, $\mathrm{Y}$ is tensile strength response, A is Aerosil 200, and B is PEG 6000.

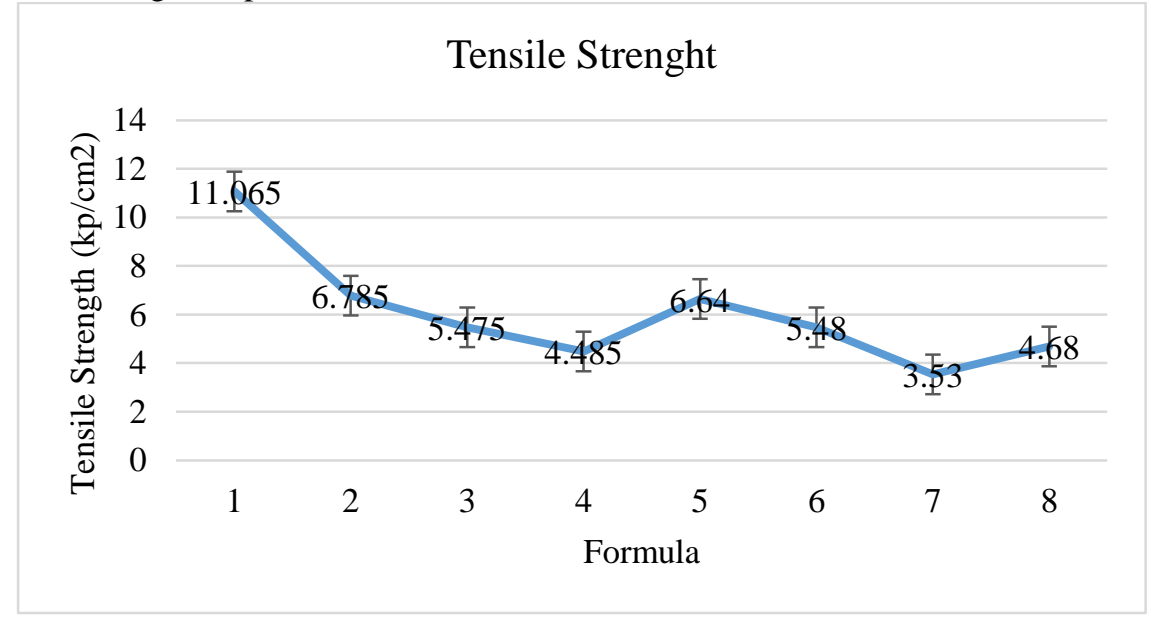

FIGURE 2. Tablet tensile strength

Equation (4) showed that aerosil 200 had smaller positive coefficient value $(4,89)$ compared with PEG 6000 (7.66). It showed that PEG 6000 had a more positive effect in increasing tablets tensile strength compared to Aerosil 200. Aerosil 200 can provide plastic deformation that indicating increased compressibility [13]. It has amorphous properties, ductile and low density, therefore the higher the aerosil, the more difficult tablets were pressed to be compact and solid. PEG with high molecular weight can effectively function as a tablet binder. Therefore, the combination of Aerosil 200 and PEG 600 would decrease the tablets tensile strength as indicated by the negative coefficient value of Aerosil 200 and PEG 6000 $(2,38)$. Figure 2 shows that the higher the concentration of PEG 6000, the higher the value of tablet tensile strength and the higher the concentration of Aerosil 200, then the value of tensile strength is getting decreased. 
The results of tablet friability test of 8 formulas are seen in FIGURE 3. The formula which had the highest tablet friability was Formula 7 (aerosil 200, 20 $\mathrm{mg}$, PEG $6000,10 \mathrm{mg}$ ) at $1.585 \%$. While The formula which has the lowest tablet friability was Formula 6 (aerosil 200, $25 \mathrm{mg}$, PEG 6000, $5 \mathrm{mg}$ ) at
$0.655 \%$. Variations in the concentration of Aerosil 200 and PEG 6000 affected the tablets friability. The SLD equation for the components of Aerosil 200 and PEG 6000 toward the tablet friability response was equation (5).

$$
\mathrm{Y}=0.79(\mathrm{~A})+0.84(\mathrm{~B})+1.65(\mathrm{~A})(\mathrm{B})
$$

Where, Y is tablet friability response, A is Aerosil 200, and B is PEG 6000.

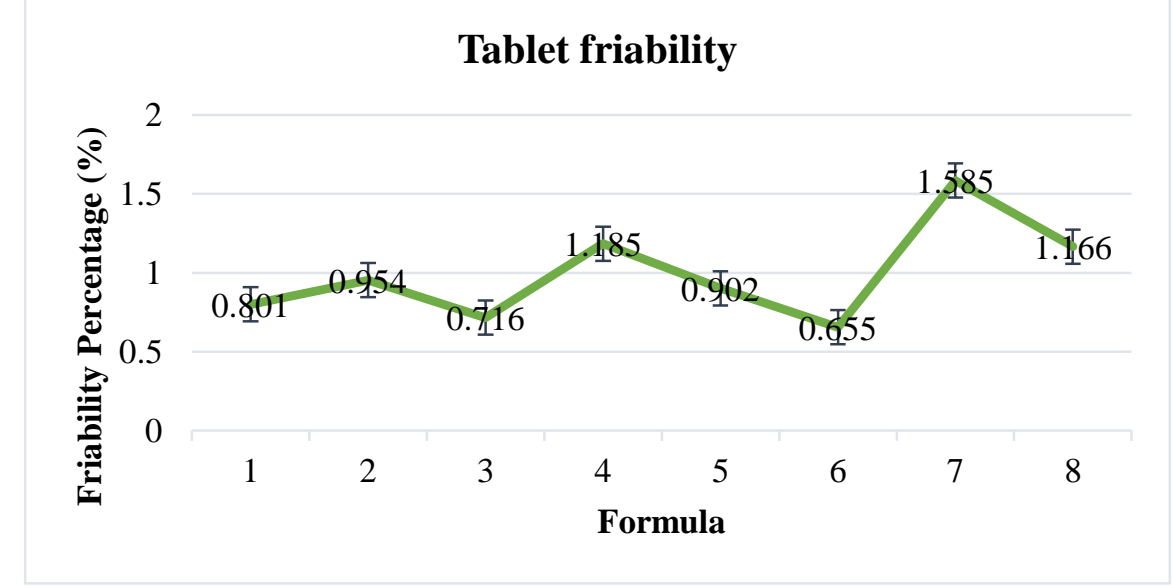

FIGURE 3. Tablet friability

Equation (5) showed that aerosil 200 had smaller value of coefficient positive $(0,79)$ compared with PEG 6000 (0.84), thus aerosil has a greater effect on the tablets friability compared with PEG. It is because aerosil 200 is ductile, thus when it was pressed it can form a compact tablets mass but it can change back to its original shape which causes the tablets mass to expand and the tablet become easily friable. It was reinforced by the positive interaction value of aerosil 200 and PEG 6000 (1,65), meaning that the combination of aerosil 200 and PEG 6000 is able to increase the tablets friability. The relationship between Aerosil 200 and PEG 6000 on the tablet's friability response is shown in figure 3 which shows the combination of concentration of Aerosil 200 and PEG 6000 with the same amount that will increase the percentage of tablets friability.

The tablet disintegration time of the eight formulas has met the requirements, that the tablet is completely dissolved without leaving the tablet core on the disintration tester. When the tablet is not completely chewed by the patient, that can cause gastrointestinal obstruction. To prevent that matter, the tablet disintegration time should be as short as possible.

Optimum formula verification: The optimum formula of spirulina chewable tablet was obtained using the simplex lattice design method from Design Expert with optimized physical response test parameters which were tablet weight uniformity, tablet hardness, tablet friability and tablet disintegration time. The independent variables used were concentration of aerosil 200 and PEG 6000. The optimum formula was determined based on the target response which wanted to be achieved and the degree of importance. There were several options of target determination; minimize, maximize, target, in range and equal to and also lower and upper limit. The degrees of importance were determined from the very unimportant (+) to the most important (+++++). The most important degree showed the most important response that most influenced the optimum formula thus the results were close to expectation.

The predicted results of the SLD method provi ded a solution of 1 formula consisting of a combination of $25 \mathrm{mg}$ Aerosil 200 and $5 \mathrm{mg}$ PEG 6000. The optimum formula of produced spirulina chewable tablets from the SLD method expert design program 7.1.5 were formulated and tested for its physical properties.

The results of the actual physical properties test conducted by the researcher were verified by comparing them with the value of predicted SLD response using one-sample t-test version 15.0 with $95 \%$ confidence level. The significant results of the one-sample t-test showed the comparison between the predicted and experimental results can be seen in table V. 
Table V. The significant level of differences between SLD optimum formula prediction against actual result

\begin{tabular}{lccc}
\hline \multicolumn{1}{c}{ Respon } & $\begin{array}{c}\text { SLD } \\
\text { prediction }\end{array}$ & Actual result & $\begin{array}{c}\text { Sig. } \\
(2 \text { tailed })\end{array}$ \\
\hline Weight uniformity $(\%)$ & 0.619 & 0.581 & 0.659 \\
Tensile strength $\left(\mathrm{kp} / \mathrm{cm}^{2}\right)$ & 4.89 & 4.52 & 0.142 \\
Tablet friability $(\%)$ & 0.795 & 0.738 & 0.089 \\
\hline
\end{tabular}

Table V shows the comparison of experiment and predicted SLD responses, the response data were all normally distributed. The value of weight uniformity, tensile strength, friability had a significance value that is greater than 0.05 , thus the data are not significantly different. Based on the obtained results, it could be concluded that there is no significant difference between the predicted parameter values and the results of the validation therefore the developed SLD equation can be used to prepare the valid tablet formula.

Hedonic test: Hedonic test of tablet appearance, taste and, aroma was conducted to the optimal formula aerosil 200, $25 \mathrm{mg}$ and PEG 6000, $5 \mathrm{mg}$. The test results of the tablets appearance showed as much as $65 \%$ of respondents expressed like slightly and $35 \%$ expressed likes. Some respondents expressed like slightly was due to the lack of attractive colors of chewable tablets that there is no additional coating material. Another result showed that $100 \%$ respondent expressed that they liked the taste of chewable tablet. The sweet flavor of the saccharine fitted well and made the taste easily acceptable for the respondents when it was chewed. The last result of hedonic test was about the aroma of chewable spirulina tablets. Fifteen percent of respondents expressed dislikes, $75 \%$ expressed like slightly and $10 \%$ expressed likes. This were caused by the tablet has not added a mask odor to the formula, so that the distinctive smell of spirulina was still being smelled. Based on the result, it is necessary to add mask odor to minimize the characteristic aroma and the coating material to beautify physical appearance of spirulina the chewable tablet.

\section{CONCLUSION}

The SLD predicted results provide a solution of an optimum formula consisting of a combination of $25 \mathrm{mg}$ aerosil 200 and $5 \mathrm{mg}$ PEG 6000. The value of weight uniformity, tensile strength, friability and tablets disintegration time have a significance value that is greater than 0.05 thus the data are not significantly different so the results of SLD equation can be used to prepare the valid formula.

\section{REFERENCES}

[1] Féfé K. M., Kikuni T., Adolphine B. N., Aimé K. L., and Michel N. A., 2016, Spirulina Supplements Improved the Nutritional Status of Undernourished Children Quickly and Significantly: Experience from Kisantu, the
Democratic Republic of the Congo, International Journal of Pediatrics, Hindawi

[2] Lorenz, R.T., 2002, Spirulina Microalgae, Cyanotech Corporation, USA

[3] Hanaa H. A. E., Farouk K. E.and Gamal S.E., 2003, Spirulina Species as a Source of Carotenoids and a-Tocopherol and its Anticarcinoma Factors, Journal of Biotechnology, Science Alert

[4] Kenfack A. M., Edie D.S., Loni E.G., Onana E.A., Sobngwi E., Gbaguidi, E., Ngougni K. A.L.,7 Tsague G.N.,4 Weid, D.V., Njoya O.,and Ngogang J.,2011, Nutritional Supplement in Malnourished HIV-Infected Adults in SubSaharan Africa: A Randomised, Single-Blind Study, Journal of Nutrition and Metabolic Insights : SAGE Journals

[5] Rowe, R.C., Sheskey, P.J., and Quinn, M.E., 2009, Handbook of Pharmaceutical Excipients, Sixth edition, Pharmaceutical Press, London.

[6] BPOM, 2014, Peraturan Kepala Badan Pengawas Obat dan Makanan Republik Indonesia Nomor 12 tahun 2014 tentang Persyaratan Mutu Obat Tradisional, Menkes RI, Jakarta

[7] FDA, 2018, Quality Attribut Considerations for Chewable Tablets Guidance for Industry, U.S. Department of Health and Human Services, Food and Drug Administration, Center for Drug Evaluation and Research (CDER). http://www.fda.gov/Drugs/GuidanceCompliance RegulatoryInformation/Guida nces/default.htm.

[8] Anonim, 2014, Farmakope Indonesia Edisi V, Departemen Kesehatan Republik Indonesia, Jakarta.

[9] Anonim 2015, United States PharmacopeiaNational Formulary 38th Edition, United Book Press, Inc., Baltimore, MD: USA

[10] Nurani, L.H., Fatimah, S.T., dan Arovah, N.I., 2017, Tablet kunyah Spirulina terstandar dan validasi metode analisis $\beta$ karoten dengan KLT Densitometri serta penetuan kadaluarsanya, Laporan Penelitian Strategis Nasional Institusi, Universitas Ahmad Dahlan, Yogyakarta.

[11] Yozo K. Masatoshi Y. and Shuji M, 2020, Effect of particle size distribution on flowability of granulated lactose, Advanced Powder Technology Journal: Elsevier, Volume 31, Issue 1, January 2020.

[12] Pramulani M. L., Ari W., Hani A., 2019, The Effect of Pregelatinized Taro Starch (Colocasia Esculenta (L.) Schott) Temperature as Filler on Thiamine Hidrochloride Tablet, Herbal Medicine 
in Pharmaceutical and Clinical Sciences: ID Design Press.

[13] Brahmaiah B., Varun D., Vijay K., Suryakanta S., Sarwar Beg., 2019, Quality-by-Design based development and characterization of pioglitazone loaded liquisolid compact tablets with improved biopharmaceutical attributes, Journal of Drug Delivery Science and Technology: Elsevier, Vol. 51, Pages 345-355. 